\title{
From Chaos to Order: Chain-Length Dependence of the Free Energy of Formation of Meso-Tetraalkylporphyrin Self-Assembled Mono- layer Polymorphs
}

\author{
Jeffrey R. Reimers, ${ }^{1-3}$ Dwi Panduwinata, ${ }^{3}$ Johan Visser, ${ }^{3}$ Yiing Chin, ${ }^{3}$ Chunguang Tang, ${ }^{3}$ Lars Goerigk, ${ }^{4}$ \\ Michael J. Ford, ${ }^{2}$ Maxine Sintic, ${ }^{3}$ Tze Jing Sum, ${ }^{3}$ Michiel J. J. Coenen, ${ }^{5}$ Bas L. M. Hendriksen, ${ }^{5}$ Johannes \\ A. A. W. Elemans, ${ }^{5}$ Noel S. Hush, ${ }^{3,5}$ and Maxwell J. Crossley ${ }^{3}$. \\ ${ }^{1}$ Centre for Quantum and Molecular Structures, College of Science, Shanghai University, Shanghai, 200444, China \\ ${ }^{2}$ School of Mathematical and Physical Sciences, The University of Technology, Sydney, NSW 2007, Australia \\ ${ }^{3}$ School of Chemistry, The University of Sydney, NSW 2006, Australia \\ ${ }^{4}$ School of Chemistry, The University of Melbourne, VIC, Australia \\ ${ }^{5}$ Radboud University Nijmegen, Institute for Molecules and Materials, Heyendaalseweg 135, 6525 AJ Nijmegen, The Nether- \\ lands \\ ${ }^{6}$ School of Biomolecular Science, The University of Sydney, NSW 2006, Australia
}

\begin{abstract}
We demonstrate that systematic errors can be reduced and physical insight gained through investigation of the dependence of free energies for meso-tetraalkylporphyrin self-assembled monolayers (SAMs) polymorphism on the alkyl chain length $m$. These SAMs form on highly-ordered pyrolytic graphite (HOPG) from organic solution, displaying manifold densities and atomic structures. SAMs with $m=11-19$ are investigated experimentally while those with $m=6-28$ are simulated using density-functional theory (DFT). It is shown that for $m=15$ or more the alkyl chains "crystallize" to dominate SAM structure. Meso-tetraalkylporphyrin SAMs of length less than 11 have never been observed, a presumed effect of inadequate surface attraction. Instead, we show that free energies of SAM formation actually enhance as the chain length decreases. The inability to image regular SAMs stems from the appearance of many polymorphic forms of similar free energy, preventing SAM ordering. We also demonstrate a significant odd/even effect in SAM structure arising from packing anomalies. Comparison of the chain-length dependence of formation free energies allows the critical dispersion interactions between molecules, solvent, and substrate to be directly examined. Interpretation of the STM data combined with measured enthalpies indicates that Grimme's "D3" explicit-dispersion correction and the implicit solvent correction of Floris, Tomasi and Pascual Ahuir are both quantitatively accurate and very well balanced to each other.
\end{abstract}

\section{Introduction}

Self-assembled monolayers $(\mathrm{SAM}) \mathrm{s}$ of various free-base $\left(\mathrm{C}_{\mathrm{m}} \mathrm{P}\right)$ and metal-substituted meso-tetraalkylporphyrins, ${ }^{1-6} \quad\left(\mathrm{M}-\mathrm{C}_{\mathrm{m}} \mathrm{P}\right.$, Scheme 1) or related octaethyl porphyrins ${ }^{7}$ have been observed using scanning-tunneling microscopy (STM) at the interfaces of organic liquids and highly-ordered pyrolytic graphite (HOPG) or $\mathrm{Au}(111)$ surfaces, and many of these have also been simulated using a priori computational methods. ${ }^{1,4}$ These SAMs are of particular note as various 2-D polymorphs have been observed for meso-tetraalkylporphyrin SAMs with chain lengths of $m=$ 11 or 13 , allowing basic mechanisms driving the production of these SAMs to be investigated under controlled conditions. To date, no such SAMs have been imaged for $m<11$, and polymorphism has not been found for $m=12$ or $m>13$, and many basic questions concerning these phenomena remain to be answered.

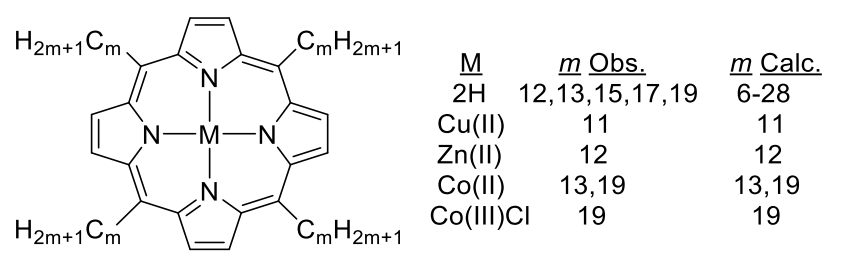

Scheme 1. Meso-tetraalkylporphyrins

Formed SAMs respond to dynamic concentration changes only near defects and so are kinetically trapped, ${ }^{5,6}$ an effect now being widely observed. ${ }^{7-19}$ However, qualitative studies indicate that higher porphyrin concentrations drive the formation of denser polymorphs and so we have introduced the hypothesis ${ }^{1}$ that the first few seconds of SAM formation are under thermodynamic control. During this time, monolayer domains start to form that henceforth become kinetically trapped, no longer being able to respond to applied stimuli. Free-energy simulations of kinetically trapped SAMs with $m=11$ and 13 support this hypothesis. ${ }^{1}$ Recently, Mazur and Hipps reviewed this field, concluding that both experimental and computation- 
al methods for studying large-scale SAM self assembly are in their infancy, ${ }^{8}$ with the need for high-quality calculations as part of experimental studies being identified. ${ }^{8,20}$ Also, the thermodynamics of SAMs formed by hydrophobic interactions is now known to be controlled by a delicate balance of entropy and enthalpy effects. ${ }^{1,14}$ One useful way to investigate this process is by utilizing different solvents ${ }^{19}$ as the differential solvation of the SAM, dissolved molecule, and bare surface contributes significantly to these terms.

We show that the problem can be simplified and significant results obtained by exploiting a chemical degree of freedom- the dependence of polymorphism on the chain length $m$. Focus is on free-energy calculations performed using density-functional theory (DFT) for meso-tetraalkylporphyrin SAMs with $m=6-28$ (Scheme 1). Results are compared to observed SAM properties for $m=11,12,13,15,17$, and 19 , presenting here the first syntheses and measurement of the $m=15$ and 17 species needed to facilitate this chain-length-dependence study.

Known structures are considered for the SAMs on HOPG of $\mathrm{Cu}(\mathrm{II})-\mathrm{C}_{11} \mathrm{P}^{6,21}$ in octanoic acid, $\mathrm{C}_{12} \mathrm{P}$ and $\mathrm{Zn}(\mathrm{II})-\mathrm{C}_{12} \mathrm{P}$ in $n$ tetradecane, ${ }^{2,3} \mathrm{C}_{13} \mathrm{P}$ and $\mathrm{Co}(\mathrm{II})-\mathrm{C}_{13} \mathrm{P}$ in 1-phenyloctane, ${ }^{1}$ as well as $\mathrm{C}_{19} \mathrm{P}$ in 1-phenyloctane; ${ }^{4}$ our new results for $\mathrm{C}_{15} \mathrm{P}$ and $\mathrm{C}_{17} \mathrm{P}$ are also measured in 1-phenyloctane. Hence this data set contains variations in not only the chain length but also in both the solvent and porphyrin metalation. While the differences induced by the solvent variations could be significant and are worthy of investigation, we proceed assuming that, for the properties of interest, these are not as important as the effects induced by varying the chain length. To date, only negligible changes in SAM structure have been observed following metalation by 4-coordinate or 5-coordinate species such as $\mathrm{Cu}(\mathrm{II})$, $\mathrm{Zn}(\mathrm{II})$, and $\mathrm{Co}(\mathrm{II})^{1,3,6}$ As reversible complexation of $\mathrm{O}_{2}$ with $\mathrm{Co}(\mathrm{II})$-porphyrin SAMs on HOPG has recently been observed, ${ }^{22}$ we synthesise and image SAMs of a $\mathrm{Co}(\mathrm{III}) \mathrm{Cl}$ porphyrin as well. The results verify that the chain-length dependence is the major affect controlling the observed property variations.

The DFT calculations are performed using a dielectric solvation model designed for 1-phenyloctane but characteristic also of 1-octanoic acid and n-tetradecane. ${ }^{1} \quad$ Using alternative approaches, simple model calculations have successfully described basic SAM properties, ${ }^{18,23-26}$ while the most reliable estimates of the effects of solvent structure and entropy have come from molecular dynamics simulations using $\mathrm{DFT}^{27}$ or empirical force fields. 10,28-31 Our a-priori modelling using implicit solvation present a useful intermediary stage in which the large computational expense of molecular dynamics simulations is avoided, allowing the accurate treatment and investigation of key intramolecular, intermolecular, and surface interactions. Being generally applicable and computationally efficient, these methods allow for a wide range of systems to be studied, examining for example the effects of solvent and temperature variations as well as those induced by chemical substitution.

Recently we demonstrated that two quite different DFTbased a priori computational schemes predict the free energies of formation $\Delta \mathrm{G}$ of SAMs formed by hydrophobic forces to an accuracy of ca. $6 \mathrm{kcal} \mathrm{mol}^{-1}$ compared to rough experimental estimates based on the hypothesis that thermodynamics controls the initial stage of growth of such SAMs. ${ }^{1}$ While errors of this magnitude are much larger than those expected for stand- ard chemical modelling, the result is understandable given the large size of the system and an identified large-scale cancellation of binding, entropy, and desolvation terms that result in $\Delta \mathrm{G}$ having a magnitude that is just $3-10 \%$ of its components. While the use of an implicit solvent model and neglect of HOPG lattice relaxation could account for much of the error, systemic improvements of all aspects of the calculations are required for truly accurate predictions. ${ }^{1}$ Nevertheless, the current calculations are expected to provide significant insight into the processes driving SAM formation and polymorphism. That calculations performed using two quite different methods yield similar results is reassuring.

One of the electronic-structure methods used is a mixed quantum-mechanical / molecular mechanical (QM/MM) scheme $^{4}$ with B3LYP/6-31G $\mathrm{G}^{* 32,33}$ describing the porphyrin core and chain kinks, the AMBER force field describing the chain ends and intermolecular interactions, ${ }^{34}$ and a specialized force field that has been fitted ${ }^{35}$ to experimental thermodynamic data describing the HOPG-alkane interaction. The other method uses the PBE density functional, ${ }^{36}$ corrected for dispersion using the D3 method ${ }^{37,38}$ (PBE-D3) to describe all of these explicitly treated interactions. This general approach has proven extremely successful in chemical applications ${ }^{37-42}$ including molecular crystal formation ${ }^{40}$ and host-guest interactions. ${ }^{43}$ In addition, both the QM/MM and PBE-D3 methods are used in conjunction with the dispersion-force dielectric solvation model of Floris, Tomasi and Pascual Ahuir. ${ }^{44}$ While the solvents used do not undergo specific interactions with either the SAM or substrate, the likely presence of multiple small cavities within the SAMs demands that the solvent size be taken into account using solvent-accessible surfaces. ${ }^{1}$

The study of polymorphism and its dependence on chain length provides a simple route to the determination of principles controlling SAM formation, and these computational methods have been shown useful by predicting relative polymorph stability. ${ }^{1} \quad$ Of the polymorphs observed for tetraalkylporphyrin SAMs, the lowest density form $\mathrm{L}$ assembles with all 4 alkyl chains interacting with the HOPG surface while medium-density polymorphs $\mathrm{M}$ assemble with two chains bound and two chains dangling into solution., ${ }^{1,6}$ Our experimental analysis for $\mathrm{C}_{11} \mathrm{P}, \mathrm{C}_{13} \mathrm{P}, \mathrm{C}_{15} \mathrm{P}, \mathrm{C}_{17} \mathrm{P}$, and $\mathrm{C}_{19} \mathrm{P}$, combined with simulations for $\mathrm{C}_{6} \mathrm{P}$ to $\mathrm{C}_{28} \mathrm{P}$ (Scheme 1) allow for some significant systematic errors to be eliminated through examination of the chain-length dependence of the calculated and measured quantities rather than just their absolute values.

\section{Methods.}

The experimental and computational methods used have all been previously described. ${ }^{1}$ Also, many subtle issues concerning the calculation methods used and the factors that necessitate them have also been discussed in detail. ${ }^{45}$

Briefly, $\mathrm{C}_{15} \mathrm{P}$ and $\mathrm{C}_{17} \mathrm{P}$ were synthesised in gram amounts by the method of Crossley et al.; ${ }^{46}$ characterization data is provided in Supporting Information (SI). Three droplets of a $4 \mathrm{mM}$ solution in distilled 1-phenyloctane were deposited on freshly cleaved HOPG (SPI Supplies) using a pipette and STM measurements were conducted in constant-current mode under ambient conditions using a PicoPlus STM (Agilent Technologies), with the STM tips prepared from mechanically cut Pt/Ir (80:20) wire of diameter $0.2 \mathrm{~mm}$ (SPI Supplies). STM images are cali- 
brated internally ${ }^{4}$ to high accuracy by changing the bias voltage during scans ${ }^{47}$ to reveal both substrate and SAM in each image. Results were then averaged over 37 images for $\mathrm{C}_{15} \mathrm{P}$ and 52 images for $\mathrm{C}_{17} \mathrm{P}$, these images being scanned in different directions to verify the accuracy of the calibration procedure. Co(II)$\mathrm{C}_{19} \mathrm{P}$ and $\mathrm{Co}(\mathrm{III}) \mathrm{Cl}-\mathrm{C}_{19} \mathrm{P}$ were synthesised from previously prepared $^{4} \mathrm{C}_{19} \mathrm{P}$ and characterized (see $\mathrm{SI}$ ), with deduced lattice parameters averaged over 35 STM scans.

The QM/MM calculations were performed using GAUSSIAN, ${ }^{48}$ adding the alkyl-chain to HOPG MM force field $^{35}$ using the EXTERNAL command in a standard QM/MM $\mathrm{ONIOM}^{49}$ calculation. A real-space sum over replicated images of the incommensurate HOPG and SAM lattices is used to treat long-range interactions. Phonon modes are included during evaluation of the zero-point energy, enthalpy, and entropy thermodynamic corrections ${ }^{50}$ using a real-space grid of $5 \times 5$ SAM unit cells. ${ }^{1}$ The PBE-D3 calculations were performed using the VASP package. ${ }^{51,52}$ The HOPG was represented using a 4-layer slab model containing a single mesotetraalkylporphyrin molecule per unit cell, with a large vacuum region between slabs. For each sample, the structure of lowest free-energy was selected by optimizing coordinates at $12-15$ different SAM lattices constrained to be commensurate with the HOPG. ${ }^{45}$ Using a specially modified version of VASP, periodic imaging of the dispersion interactions is not performed in the direction normal to the SAM surfaces, as is required to implement a two-dimensional slab calculation, and not performed at all for "isolated" molecule calculations. All calculations are performed at the gamma-point of the Brillouin zone using the default cuttoff of $300 \mathrm{eV}$ for the plane waves. The thermal corrections evaluated using $\mathrm{QM} / \mathrm{MM}$ were added to the PBE-D3 binding energies. Only gas-phase structures are generally optimized using either QM/MM or PBE-D3, with solvation energy corrections evaluated only at the resultant optimized structures. For one structure type (later called "Mb"), tight internal cavities made the optimized geometry solvent dependent, and in this case the geometry was optimized in solvent. Automated schemes to perform this task are becoming available in VASP. ${ }^{53}$ Details of these solvation-energy calculations, which are based on the solvent-accessible surfaces of the molecule, raw HOGP surface, and SAM, are described elsewhere. ${ }^{1}$ Reported net solvation energies are obtained as the difference between the solvation energies of the SAM and the sum of those for the isolated HOPG surface and the dissolved molecule. ${ }^{1}$ STM images are simulated from the VASP output using the Tersoff-Hamann approximation $^{54}$ at a bias voltage of $0.8 \mathrm{~V}$.

\section{Results and Discussion.}

a. Atomic structure of the $\mathrm{L}$ polymorphs. Some observed STM images for $\mathrm{C}_{15} \mathrm{P}$ and $\mathrm{C}_{17} \mathrm{P}$ on $\mathrm{HOPG}$ in 1-phenyloctane are shown in Fig. 1 and in SI Figs. S1 and S2. In Fig. 1 these images are extracts taken from larger-area images overlayed with fitted SAM lattice vectors (yellow) and calculated atomic structures (red), whereas in the SI Figs. S1 and S2 full DFT simulated images are compared with raw observed ones. The highresolution structure of the chains on the surface is resolved, as is the internal structure in and around the macrocycle rings, facilitating detailed comparison with the calculated images. This comparison allows the identification of the atomic structures of the SAMs with high reliability. Figure 2 shows latticevector definitions appropriate for these SAMs, with their meas- ured and calculated values compared in Table 1. Good agreement between the QM/MM and observed data is immediately evident. As has been found before, tetraalkylporphyrin SAMs on HOPG have lattice parameters incommensurate with the substrate. ${ }^{4,6,55}$ Hence accurate calculations are not currently feasible using PBE-D3 as the closest commensurate lattices must be used in the VASP calculations. Nevertheless, the PBE-D3 results support the structural assignments as always the commensurate lattice closest to the observed one is found to have the lowest calculated Gibbs free energy per unit surface area $\Delta \mathrm{G} / \mathrm{A}$.

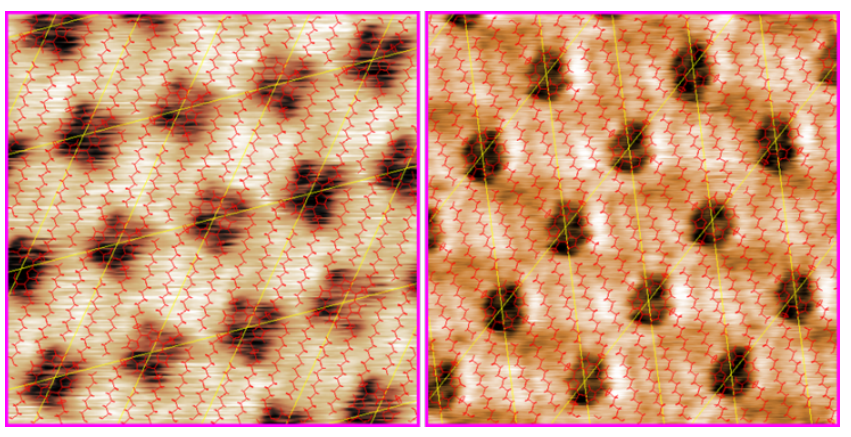

Fig. 1. Observed constant-current STM images in reversed contrast (tip high is black, tip low is white) for left- $\mathrm{C}_{15} \mathrm{P} \mathrm{L}$ (bias $=-0.786 \mathrm{~V}$, setpoint current $=50 \mathrm{pA}$, image calibrated to $88.0 \AA \times 74.7 \AA, x \mathrm{Oy}=$ $87.9^{\circ}$ ) and right $\mathrm{C}_{17} \mathrm{P}$ L (bias $=-0.430 \mathrm{~V}$, setpoint current $=10 \mathrm{pA}$, image calibrated to $89.6 \AA \times 82.5 \AA, x \mathrm{O} y=88.5^{\circ}$ ) on HOPG from 1-phenyloctane solution, with overlayed lattice vectors (yellow) and $\mathrm{QM} / \mathrm{MM}$ calculated structures (red).

The observed SAMs for $\mathrm{C}_{15} \mathrm{P}$ and $\mathrm{C}_{17} \mathrm{P}$ correspond to the $\mathrm{L}$ polymorphs previously observed for $\mathrm{C}_{11} \mathrm{P},{ }^{6,21} \mathrm{C}_{13} \mathrm{P},{ }^{1}$ and $\mathrm{C}_{19} \mathrm{P}^{4}$ For all of these SAMs plus related metallated SAMs, the observed and QM/MM-calculated lattice parameters are shown in Fig. 2 and SI Table S1. This data includes results from new STM images (SI Fig. S3) for $\mathrm{Co}(\mathrm{II})-\mathrm{C}_{19} \mathrm{P}$ and $\mathrm{Co}(\mathrm{III}) \mathrm{Cl}_{-} \mathrm{C}_{19} \mathrm{P}$ and depicts smooth variations of properties with chain length but little metalation dependence. Even 6-coordinate metal substitution in $\mathrm{Co}(\mathrm{III}) \mathrm{Cl}-\mathrm{C}_{19} \mathrm{P}$ does not affect the lattice, indicating that the chloride ligand sits on the solution side of the macrocycle rather than between it and the HOPG. Also shown in SI Fig. $\mathrm{S} 3$ are images of mixed $\mathrm{Co}(\mathrm{II})-\mathrm{C}_{19} \mathrm{P}$ and $\mathrm{Co}(\mathrm{III}) \mathrm{Cl}_{-} \mathrm{C}_{19} \mathrm{P}$ monolayers, indicating that these species with quite different STM profiles can readily mix in SAMs. The $\mathrm{Co}(\mathrm{II})-\mathrm{C}_{19} \mathrm{P}$ images indicate no complexation by $\mathrm{O}_{2}{ }^{22}$

Looking at the structural results in greater detail, the SAM lattice vector $b$ aligns at an angle $\alpha=10-12^{\circ}$ from the alkylchain orientation (Fig. 2) and so its length $b$ changes by on average $1.25 \AA$ per $\mathrm{CH}_{2}$, half the length of the repeat 
Table 1. Comparison of observed and calculated lattice parameters ${ }^{\mathrm{a}}$ for the $\mathrm{L}$ polymorphs of $\mathrm{C}_{15} \mathrm{P}$ and $\mathrm{C}_{17} \mathrm{P}$.

\begin{tabular}{|c|c|c|c|c|}
\hline Mol. & Param. & Obs. & $\mathrm{QM} / \mathrm{MM}$ & PBE-D3 ${ }^{b}$ \\
\hline \multirow[t]{7}{*}{$\mathrm{C}_{15} \mathrm{P}$} & $a(\AA)$ & $21.2 \pm 0.3$ & 20.4 & 21 \\
\hline & $b(\AA)$ & $28.5 \pm 0.6$ & 28.9 & 29 \\
\hline & $c(\AA)$ & $21.8 \pm 0.5$ & 22.4 & \\
\hline & (०) & $49.4 \pm 0.5$ & 50.5 & 53 \\
\hline & $\phi(\circ)$ & $83.0 \pm 1.6$ & 84.9 & \\
\hline & (o) & $12.3 \pm 0.8$ & 13.0 & \\
\hline & $A\left(\AA^{2}\right)$ & $459 \pm 7$ & 453 & 486 \\
\hline \multirow[t]{7}{*}{$\mathrm{C}_{17} \mathrm{P}$} & $a(\AA)$ & $21.3 \pm 0.3$ & 20.4 & 21 \\
\hline & $b(\AA)$ & $30.9 \pm 0.3$ & 31.4 & 31 \\
\hline & $c(\AA)$ & $23.7 \pm 0.5$ & 24.5 & \\
\hline & (o) & $50.0 \pm 1.1$ & 51.4 & 54 \\
\hline & $\phi(\circ)$ & $86.5 \pm 1.4$ & 88.2 & \\
\hline & (o) & $9.9 \pm 0.6$ & 12.0 & \\
\hline & $A\left(\AA^{2}\right)$ & $503 \pm 5$ & 498 & 533 \\
\hline
\end{tabular}

${ }^{\text {a }}$ The lattice vector lengths $a, b$, and $c$, angles $\theta$ and $\phi$, and orientation $\alpha$ to the HOPG $<1 \quad 1-20>$ lattice vector are defined in Fig. 2 whilst $A$ is the surface-cell substrate area. ${ }^{b}$ parameters of the lowest free-energy commensurate lattice: the weak dependence of the energy on $\alpha$ therefore cannot be determined whilst the other parameters are only indicative.

unit of the alkane chain. The length $a$ and angle $\theta$ between the $\mathbf{a}$ and $\mathbf{b}$ vectors vary little, indicating that the chain kinks and macrocycle rings always stack together in the same pattern. These properties combine to determine the other observed lattice features: the length of the $\mathrm{c}$ vector increases with length but at a slower rate than for $\mathrm{b}$, while the angle $\phi$ slowly increases and the covered substrate surface-area $A$ increases by $26 \AA^{2}$ per $\mathrm{CH}_{2}$. The alkyl chains align nearly parallel to the HOPG

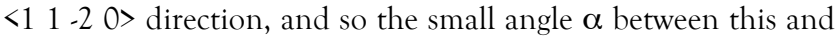
the $\mathbf{b}$ vector slowly decreases with increasing chain length. The calculated lattice properties accurately reproduce all observed features.

b. The chain-length dependence of the $\mathrm{L}$ polymorphs. In solution or in the gas phase, the alkyl chains prefer to be straight and to leave the macrocycle plane at an angle of ca. $45^{\circ}$ whereas in the SAM they kink near the $\gamma$ carbon to lie flat on the surface. ${ }^{4}$ In $\mathrm{L}$ polymorphs, all 4 chains kink this way whereas for $\mathrm{M}$ two chains project into the solution instead. Understanding SAM formation and polymorphism thus requires understanding the effects that chain conformation has on the intermolecular attraction, the interaction with the HOPG, the solvent interaction, the entropy, and hence the free energy of formation. ${ }^{1}$

Initially ${ }^{4}$ we considered 5 possible structures for the chain kinks of the $\mathrm{L}$ polymorph of $\mathrm{C}_{19} \mathrm{P}$, evaluating only the energy of binding $\Delta E / n$ where $n$ is the number of moles of porphyrin in the SAM. One low energy structure, here named La, was found, and indeed this is the structure type shown to depict many observed properties in Figs. 1-2, Table 1, etc.. The other four alternatives had $\Delta E / n$ values less attractive by $11-23 \mathrm{kcal}$ $\mathrm{mol}^{-1}$ and were deemed uncompetitive. Table 2 shows the
QM/MM calculated free energies of formation $\Delta G / n$ for all 5 structures (here named La-Le) for $\mathrm{C}_{11} \mathrm{P}, \mathrm{C}_{13} \mathrm{P}, \mathrm{C}_{15} \mathrm{P}, \mathrm{C}_{17} \mathrm{P}$, and $\mathrm{C}_{19} \mathrm{P}$, revealing that the alternative structures Lb-Le are predicted to be at least $6 \mathrm{kcal} \mathrm{mol}^{-1}$ higher in free energy. It therefore appears that the calculations are capable of predicting the observed polymorph structure as well as simply identifying it- the structures are identified by comparing the predicted lattice parameters and STM images for Lb-Le with experiment, see e.g., Table S1. Note that the Ld and Le structure series present the alkyl chains with their C-C bond plane perpendicular to the surface whereas La-Lc have the chains parallel; optimized atomic coordinates and pictorial views for all structures are given in SI Sect. S4.

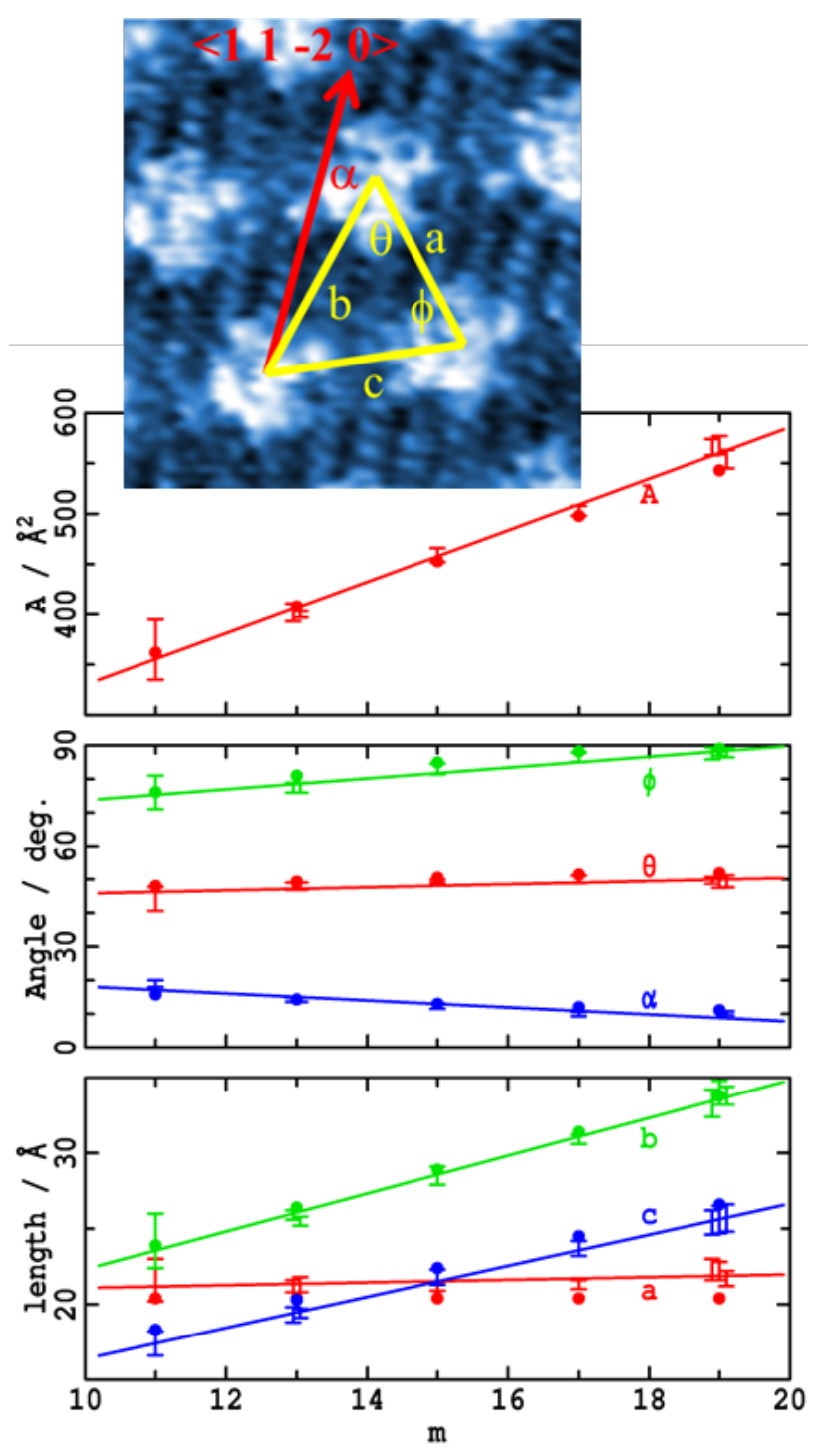

Fig. 2. Shown for the L polymorphs of tetraalkylporphyrins SAMs $\mathrm{C}_{\mathrm{m}} \mathrm{P}$ on HOPG from solution are variation of observed (error bars with linear fit) and calculated (filled circles) lattice parameters. Points marked "II" or "III" indicate the metal valence of related metallated porphyrins $M-C_{m} P$. The insert defines the lattice lengths $a, b$, and $c$, angles $\theta$ and $\phi$, and orientation $\alpha$ to the HOPG $<1 \quad 1-20>$ vector; $A$ is the substrate surface-cell area). 
Table 2. Calculated free-energies $\Delta \mathrm{G} / \mathrm{n}$ of SAM formation per mole of porphyrin, in kcal mol ${ }^{-1}$, for the $\mathrm{L}$ polymorph of tetraalkylporphyrin SAMs $\mathrm{C}_{m} \mathrm{P}$ for $m=6$ to 28 .

\begin{tabular}{|c|c|c|c|c|c|c|c|c|c|c|c|c|c|c|}
\hline Method & Str. & $m=$ & & 7 & 9 & 11 & 13 & 15 & 17 & 19 & 21 & 23 & 25 & 27 \\
\hline \multirow[t]{5}{*}{$\mathrm{QM} / \mathrm{MM}$} & $\mathrm{La}$ & & & -7.7 & -6.3 & -5.8 & -6.1 & -6.5 & -7.2 & -7.5 & -9.8 & -10.3 & -11.2 & -11.7 \\
\hline & $\mathrm{Lb}$ & & & & & a & a & 16.6 & 15.5 & 15.4 & & & & \\
\hline & $\mathrm{Lc}$ & & & & & 5.3 & 5.3 & 5.1 & 5.0 & 4.3 & & & & \\
\hline & $\mathrm{Ld}$ & & & & & 1.2 & 1.3 & 1.2 & 0.6 & -1.2 & & & & \\
\hline & Le & & & & & 7.0 & 7.8 & 8.1 & 7.5 & 6.6 & & & & \\
\hline \multirow[t]{2}{*}{ PBE-D3 } & $\mathrm{La}$ & & & -3.7 & -3.8 & -3.5 & -4.4 & -6.4 & -6.5 & -7.2 & -10.5 & -12.3 & & \\
\hline & & $m=$ & 6 & 8 & 10 & 12 & 14 & 16 & 18 & 20 & 22 & 24 & 26 & 28 \\
\hline $\mathrm{QM} / \mathrm{MM}$ & $\mathrm{La}$ & & -11.7 & -7.7 & -5.6 & -5.6 & -5.8 & -5.8 & -6.0 & -6.2 & -7.0 & -7.8 & -8.2 & -8.7 \\
\hline PBE-D3 & $\mathrm{La}$ & & -2.7 & -4.7 & -2.2 & -2.9 & -3.5 & -3.3 & -4.5 & -5.1 & -7.2 & -8.2 & & \\
\hline
\end{tabular}

a: unstable, collapses to a lower-energy polymorph

Note that a SAM covers a fixed macroscopic surface area and so the critical thermodynamic quantity is not the free energy change per mole of porphyrin $\Delta \mathrm{G} / n$ (as listed in Table 2) but rather the free energy change per unit of surface area $\Delta G / A$. As structures La-Le occupy different substrate surface areas per porphyrin molecule $A$, these quantities do not necessarily order analogously. In SI Table S5 the free energies are reported alternatively as $\Delta \mathrm{G} / \mathrm{A}$. We find that no significant order changes occur between the results given in the two tables and hence frame discussions primarily in terms of the more familiar chemical-potential expression $\Delta \mathrm{G} / n$.

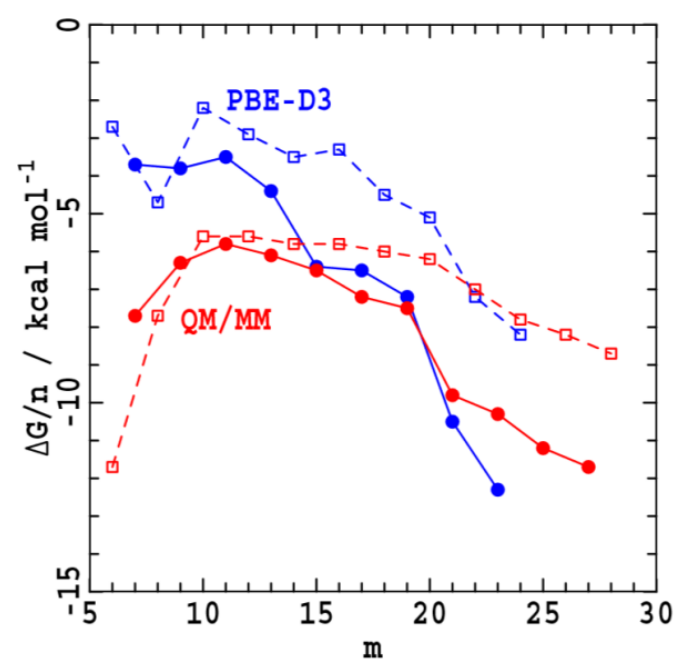

Fig. 3. Calculated free energies of formation $\Delta \mathrm{G} / \mathrm{n}$ for the La polymorph of $\mathrm{C}_{\mathrm{m}} \mathrm{P}$ on HOPG in phenyloctane, correlated according to whether $m$ is odd (solid lines) or even (dashed lines).

Fig. 3 shows the chain-length dependence of the free energies of formation $\Delta \mathrm{G} / n$ for the La structure of $\mathrm{C}_{6} \mathrm{P}$ to $\mathrm{C}_{28} \mathrm{P}$ calculated using QM/MM and PBE-D3, while Table S7 shows the breakdown of the QM/MM energy into binding, thermal, and desolvation components. SAMs form from solutions at concentrations at least as low as $10^{-6} \mathrm{M}$, implying $\Delta \mathrm{G} / n \leq-12 \mathrm{kcal}$ mol $^{-1}{ }^{1}$ The calculations predict significant variation of this quantity with increasing chain length $m$ but currently this cannot be verified. Overall, they appear to underestimate the bind- ing by of order $6 \mathrm{kcal} \mathrm{mol}^{-1}$. This could arise for many reasons including the neglect of HOPG relaxation (worth of order -1 $\left.\mathrm{kcal} \mathrm{mol}^{-1}\right)$, use of commensurate lattices in the PBE-D3 calculations (worth up to a few $\mathrm{kcal} \mathrm{mol}^{-1}$ ), or simply just errors in the QM/MM, PBE-D3, thermal or solvation contributions. Indeed, from Table S7 we see that the binding energy contributions $\Delta E / n$ range from -90 to $-290 \mathrm{kcal} \mathrm{mol}^{-1}$, the thermal corrections from 20 to $70 \mathrm{kcal} \mathrm{mol}^{-1}$, and the desolvation terms from 60 to $210 \mathrm{kcal} \mathrm{mol}^{-1}$, indicating that $\Delta \mathrm{G} / \mathrm{n}$ arises from the cancellation of many large contributions. Also the empirical D3 dispersion contribution to $\Delta E / n$ is large and critical, ranging from -107 to $-324 \mathrm{kcal} \mathrm{mol}^{-1}$ for $\mathrm{C}_{6} \mathrm{P}$ to $\mathrm{C}_{24} \mathrm{P}$, respectively. Given this, the agreement between the $\mathrm{QM} / \mathrm{MM}$ calculations, PBE-D3 calculations, and experiment is remarkable.

For longer chain lengths with $m>15$, a distinct odd/even effect is evident in Fig. 3, with the free energies of formation for odd-length chains being calculated to be ca. $3 \mathrm{kcal} \mathrm{mol}^{-1}$ more stable than those of the neighbouring even-length species. This arises because long alkyl chains align in a dense pattern that does not allow ready slippage of the chains. As a result, one of the two sets of chain ends appears compressed compared to the other in the La SAM of even-chained molecules, decreasing SAM stability, as indicated in Fig. 4. Its effects are still apparent for $m=12$ and most likely accounts for the lack of observation of an $\mathrm{L}$ polymorph for that molecule. For short chain lengths, the alkyl chain packing no longer dominates SAM structure and the molecules become flexible enough to adapt to chain-length variations. This is particularly apparent in Fig. 4 where the $\mathrm{C}_{6} \mathrm{P}$ SAM is compared to that for $\mathrm{C}_{8} \mathrm{P}$. Most relevant here is that SAMs have not been observed for chain lengths $m<$ 11 , and this was assumed to arise because long alkyl chains were necessary to provide binding. Instead the calculations predict that bonding free energies actually enhance for $m<10$, suggesting that a different explanation for the difficulty in assembling SAMs of shorter molecules needs to be found. 
Table 3. Large $m$ asymptotic contributions to the chainlength dependence $d(\Delta G / n) / d m$ of the free energy of formation of the La polymorphs (in $\mathrm{kcal} \mathrm{mol}^{-1}$ )

\begin{tabular}{llll}
\hline Contribution & Primary Source & QM/MM & PBE-D3 \\
\hline Interporphyrin & AMBER $^{\mathrm{a}}$ & -2.8 & - \\
Porph. to HOPG & Fit to Exp. $^{\mathrm{b}}$ & -6.4 & - \\
PBE & PBE $^{\mathrm{c}}$ & - & 1.4 \\
D3 & $\mathrm{D}^{\mathrm{d}}$ & - & -10.8 \\
Thermochemistry & $\mathrm{QM}^{\mathrm{d}} \mathrm{MM}^{\mathrm{e}}$ & 2.4 & {$[2.4]$} \\
Desolvation & Continuum $^{\mathrm{f}}$ & 6.6 & 6.6 \\
& Dispersion $^{\mathrm{f}}$ & & \\
Total & & -0.3 & -0.5 \\
\hline
\end{tabular}

${ }^{\text {a }}$ from AMBER force field ${ }^{34}$ used in QM/MM model. ${ }^{4}{ }^{\mathrm{b}}$ from force field fitted to alkane-HOPG thermochemical data. ${ }^{35} \mathrm{c}$ standard DFT theory ${ }^{36}$ d general dispersion correction to DFT. ${ }^{37,38}$ e entropy-dominated standard analysis ${ }^{50}$ but including ${ }^{1}$ inter-lattice phonons. ${ }^{f}$ model of Floris et al. ${ }^{44}$ recast ${ }^{1}$ to use the solventexcluded surface.
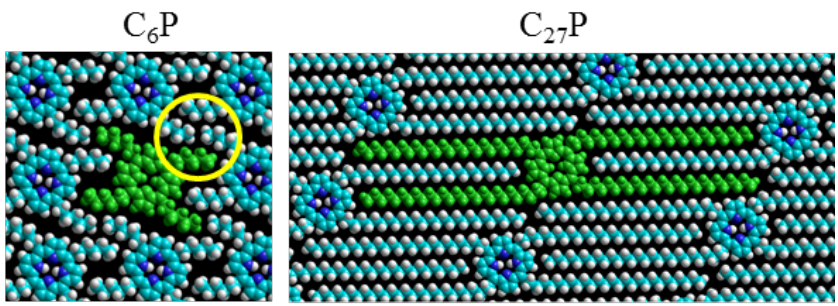

$\mathrm{C}_{8} \mathrm{P}$
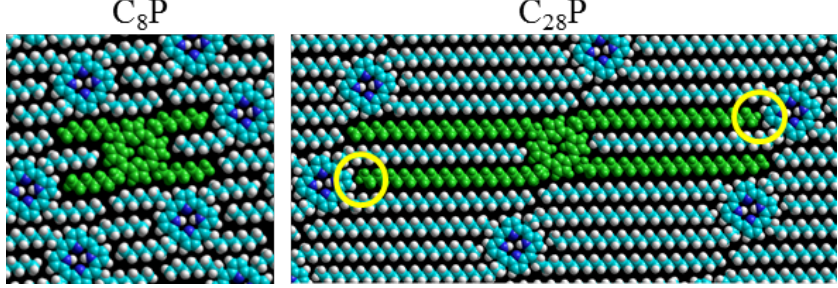

Fig. 4. QM/MM optimized La atomic structures showing the chainend compression responsible for the odd-even effect of longchained porphyrins as well as the flexibility chains for $\mathrm{C}_{6} \mathrm{P}$ compared to $\mathrm{C}_{8} \mathrm{P}$, see yellow highlighting; the HOPG substrate is omitted for clarity.

For SAMs with $m>15$, geometrical anomalies become unimportant and the free energies therefore become easier to interpret. Table 3 shows the QM/MM and PBE-D3 chain-length dependences $\mathrm{d}(\Delta \mathrm{G} / n) / \mathrm{d} m$ and their components, with the primary source of each component identified. The interporphyrin and porphyrin to HOPG contributions are predicted to lead to stronger binding by -2.8 and $-6.4 \mathrm{kcal} \mathrm{mol}^{-1}$ per increase in chain length, respectively, opposed by entropy-dominated thermochemical contributions and desolvation contributions of 2.4 and $6.6 \mathrm{kcal} \mathrm{mol}^{-1}$, respectively, giving a small net increased stabilization of just $-0.3 \mathrm{kcal} \mathrm{mol}^{-1}$. Based upon the hypothesis that thermodynamics controls the initial stage of SAM growth, if the observed value is taken to be roughly $0 \pm 1 \mathrm{kcal} \mathrm{mol}^{-1}$ and the error is associated all with the dispersive solvation energy, ${ }^{44}$ its accuracy can be estimated as $\pm 15 \%$. From the DFT results, the PBE functional is seen to increasingly oppose binding by $1.4 \mathrm{kcal} \mathrm{mol}^{-1}$ per increase in chain length whilst its D3 correction favours it at $-10.8 \mathrm{kcal} \mathrm{mol}^{-1}$, giving a net slope of $\mathrm{d}(\Delta \mathrm{G} / \mathrm{n}) / \mathrm{d} m=-0.5 \mathrm{kcal} \mathrm{mol}^{-1}$. The D3 contribution would therefore also appear to be accurate to $\pm 15 \%$. This is an upper bound to the likely D3 error as it embodies significant limitations in the observed data quality as well as in the other properties contributing to its interpretation. This is an astonishing result given the nature of the experimental data from which it was obtained.

c. The chain-length dependence of the $\mathrm{M}$ polymorphs. $\mathrm{M}$ polymorphs have been observed for $\mathrm{C}_{11} \mathrm{P}$ in 1-octanoic acid, ${ }^{6,21}$ $\mathrm{C}_{12} \mathrm{P}$ in $n$-tetradecane, ${ }^{2,3}$ and $\mathrm{C}_{13} \mathrm{P}$ in 1 -phenyloctane, ${ }^{1}$ involving different atomic structures named here $\mathrm{Ma}, \mathrm{Mb}$, and $\mathrm{Mc}$, respectively. ${ }^{1}$ This behaviour is in stark contrast to that for the $\mathrm{L}$ polymorphs for which only the La structure has been observed, independent of the chain length. To understand this complexity we optimized 40 conceived SAMs of $\mathrm{C}_{11} \mathrm{P}, \mathrm{C}_{12} \mathrm{P}$, and $\mathrm{C}_{13} \mathrm{P}$ using $\mathrm{QM} / \mathrm{MM}$. These initial structures were obtained following a systematic grid search of possible macrocycle ring orientations, kink structures associated with the two chains that lie parallel to the surface, and related distortions of the other two alkyl chains, constrained to the very restrictive requirement that all variables must combine to produce a surface-covering SAM. ${ }^{1}$ They relaxed to at most 22 unique SAM structures (named Ma$\mathrm{Mv}$ ) for which pictorial views and coordinates are provided in SI Sect. S4, with a key examples of each of the low-free-energy forms Ma-Mh highlighted in Fig. 5. The torsional angle sets for the chains not lying flat on the surface direct them to either rise quickly into solution or to turn and lie on top of either the porphyrin macrocycles or else the alkyl chains of neighbouring molecules, with 9 sets of these variables being identified as producing chemically feasible patterns. Of the 22 optimized structures per sample, only $\mathrm{Ma}$ for $\mathrm{C}_{11} \mathrm{P}, \mathrm{Mb}$ for $\mathrm{C}_{12} \mathrm{P}$, and $\mathrm{Mc}$ for $\mathrm{C}_{13} \mathrm{P}$ displayed lattice vectors (see SI Tables S2-S4) and internal STM-image structures consistent with experiment, while in addition for $\mathrm{C}_{11} \mathrm{P}$ and $\mathrm{C}_{13} \mathrm{P}$, only those structures can account for features revealed at L-M polymorph interfaces. ${ }^{1}$ Structures for the 8 nominally lowest-energy structure types Ma-Mh were also optimized (at commensurate geometries) by PBE-D3, producing analogous results.

For the QM/MM and (where available) PBE-D3 methods, Table 4 reports the free energies of formation $\Delta \mathrm{G} / n$ for each SAM, while SI Table S6 compares these to $\Delta \mathrm{G} / \mathrm{A}$, verifying that the basic pattern is maintained. Table $\mathrm{S} 8$ shows $\Delta \mathrm{G} / n$ decomposed into binding, thermochemical, and desolvation contributions. While in detail the predictions of the QM/MM and PBE-D3 calculations significantly differ, the same basic qualitative scenario for M-polymorph formation is depicted: multiple low-energy structures are possible, the number of these structures increases as $m$ decreases, and no consistent pattern emerges for the change in $\Delta \mathrm{G} / n$ as $m$ varies. Local structural effects specific to each particular chain length combined with each particular chain conformation and orientation therefore dominate SAM formation. Indeed, the 8 molecular arrangements depicted in Fig. 5 each include identifyable attract- 

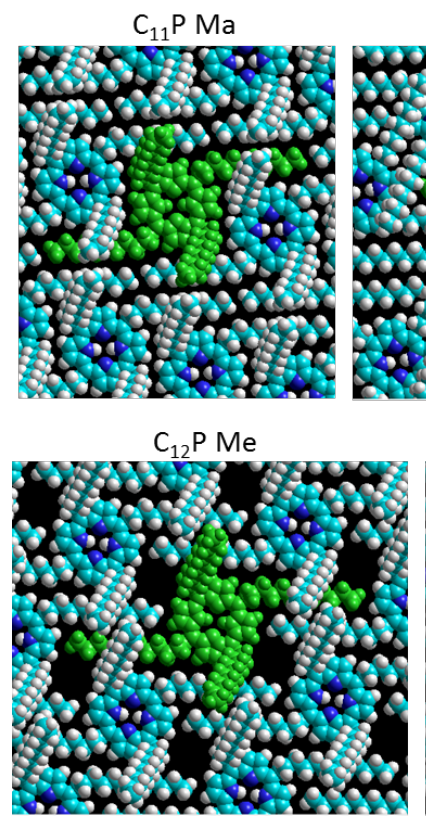

$\mathrm{C}_{12} \mathrm{P} \mathrm{Mb}$

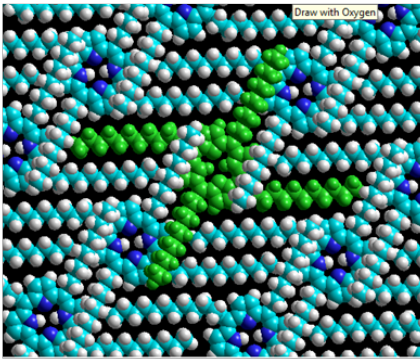

$\mathrm{C}_{11} \mathrm{P} \mathrm{Mf}$

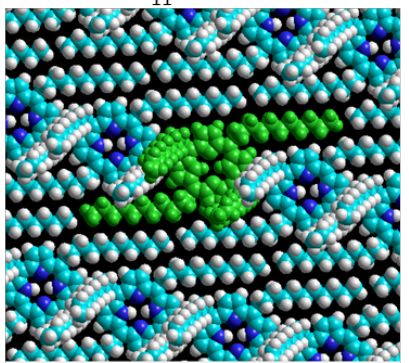

$\mathrm{C}_{13} \mathrm{P} \mathrm{Mc}$

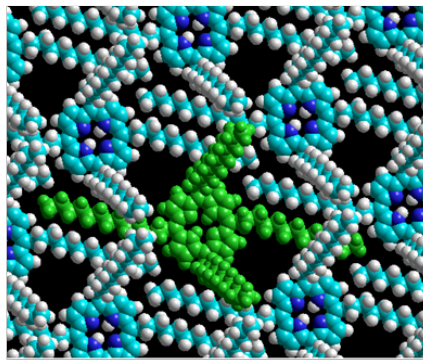

$\mathrm{C}_{11} \mathrm{P} \mathrm{Mg}$

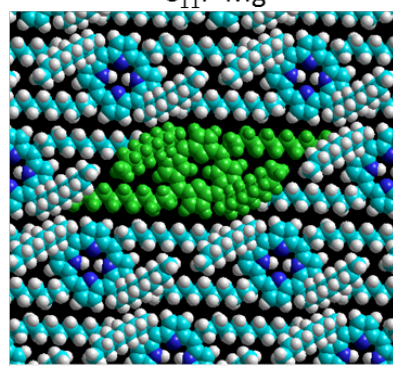

$\mathrm{C}_{13} \mathrm{P} \mathrm{Md}$

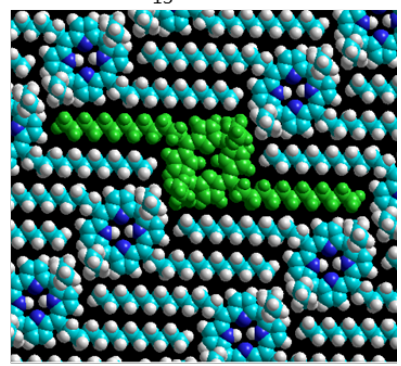

$\mathrm{C}_{13} \mathrm{P} \mathrm{Mh}$

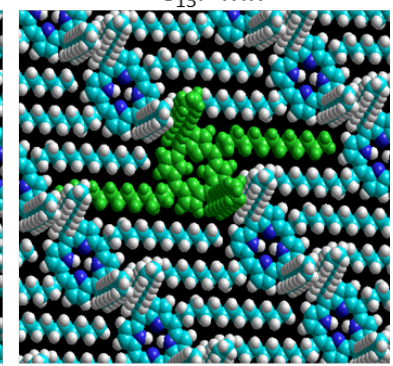

Fig. 5. QM/MM optimized atomic structures of some sample SAMs of tetraalkylporphyrins on HOPG of low free energy; the HOPG substrate is omitted for clarity.

Table 4. Calculated free-energies $\Delta \mathrm{G} / n$ of SAM formation per mole of porphyrin, for the $M$ polymorphs of tetraalkylporphyrin SAMs. ${ }^{a}$

\begin{tabular}{|c|c|c|c|c|c|c|}
\hline & \multicolumn{3}{|c|}{$\mathrm{QM} / \mathrm{MM}$} & \multicolumn{3}{|c|}{ PBE-D3 } \\
\hline & $\mathrm{C}_{11} \mathrm{P}$ & $\mathrm{C}_{12} \mathrm{P}$ & $\mathrm{C}_{13} \mathrm{P}$ & $\mathrm{C}_{11} \mathrm{P}$ & $\mathrm{C}_{12} \mathrm{P}$ & $\mathrm{C}_{13} \mathrm{P}$ \\
\hline $\mathrm{Ma}$ & -8.1 & -6.9 & -5.8 & -5.0 & -3.1 & -0.8 \\
\hline $\mathrm{Mb}$ & -10.5 & -12.0 & -10.8 & -4.2 & -6.1 & -5.2 \\
\hline $\mathrm{Mc}$ & 5.5 & -10.0 & -6.9 & 8.3 & -3.1 & -6.1 \\
\hline $\mathrm{Md}$ & -8.1 & -8.2 & -8.8 & 4.8 & -1.1 & 2.1 \\
\hline $\mathrm{Me}$ & -6.8 & -9.9 & -5.7 & -3.8 & -6.6 & -4.5 \\
\hline Mf & -7.1 & -4.9 & -4.0 & -3.9 & -3.3 & -2.0 \\
\hline $\mathrm{Mg}$ & -3.1 & -7.0 & -2.0 & -5.7 & -4.7 & 1.3 \\
\hline $\mathrm{Mh}$ & 3.5 & -6.8 & -6.6 & 1.3 & -1.7 & -2.6 \\
\hline $\mathrm{Mi}$ & -5.9 & -4.9 & -6.8 & & & \\
\hline $\mathrm{Mj}$ & -4.8 & -4.7 & -2.6 & & & \\
\hline $\mathrm{Mk}$ & 1.2 & -4.6 & -4.0 & & & \\
\hline $\mathrm{Ml}$ & -3.5 & -3.6 & 2.3 & & & \\
\hline $\mathrm{Mm}$ & -1.4 & -2.4 & -3.2 & & & \\
\hline $\mathrm{Mn}$ & -2.0 & -2.3 & -2.0 & & & \\
\hline Mo & 0.8 & -1.2 & -1.8 & & & \\
\hline $\mathrm{Mp}$ & -1.6 & 0.5 & 2.9 & & & \\
\hline $\mathrm{Mq}$ & -1.3 & 0.5 & 3.1 & & & \\
\hline $\mathrm{Mr}$ & 2.3 & 2.7 & 4.8 & & & \\
\hline Ms & 3.6 & 11.4 & unstable & & & \\
\hline Mt & 4.6 & 4.9 & 8.2 & & & \\
\hline $\mathrm{Mu}$ & 4.7 & 6.9 & 5.2 & & & \\
\hline $\mathrm{Mv}$ & 7.8 & 9.1 & 11.5 & & & \\
\hline
\end{tabular}

Experimentally observed structures highlighted in bold, this or lower-energy calculated structures are also highlighted in italics.

tive interactions between SAM components, but they manifest in each example mostly by different means. Further, it is not just these visually obvious changes in the attractive forces that control the free energies but also the differential solvation and entropy terms change significantly for each structure type. Large changes to these contributing terms cancel each other out, making the net free energy changes small.

This effect explains the difficulty in observing ordered SAMs by STM for chain lengths with $m<11$ as long-range order is difficult to achieve when many strikingly different molecular configurations can all absorbe with similar free energy. If the attraction between the molecule and surface becomes too weak, then molecules fail to stick to the surface at all. However, the identified scenario is one in which molecules continue to stick to the surface but lose the ability to order into a stable lattice. As STM images take of order $1 \mathrm{~m}$ to measure, images are only measured when the SAMs remain locked into one configuration for long periods. Inability to observe SAMs is therefore a kinetic effect, one that can only be manifested when many possible configurations share similar binding free energies.

Examining the predicted results in greater detail, the $\mathrm{QM} / \mathrm{MM}$ method appears to overstabilize $\mathrm{Mb}$, incorrectly predicting that it forms the lowest-energy $\mathrm{M}$ polymorph for $\mathrm{C}_{11} \mathrm{P}$ and $\mathrm{C}_{13} \mathrm{P}$ instead of just $\mathrm{C}_{12} \mathrm{P}$. PBE-D3 correctly predicts $\mathrm{Mc}$ to be the most stable structure for $\mathrm{C}_{13} \mathrm{P}$ but $\mathrm{Mg}$ and $\mathrm{Me}$ are incorrectly predicted to be lower in free energy than $\mathrm{Ma}$ and $\mathrm{Mb}$ by 0.7 and $0.5 \mathrm{kcal} \mathrm{mol}^{-1}$, respectively. Such differences are far below the expected accuracy of the computational method. Similarly the QM/MM method ranks the observed structure as either the most favoured or else the second most, but the free energy gaps increase to up to $4 \mathrm{kcal} \mathrm{mol}^{-1}$, a more realistic estimate of the shortcomings of the calculations. 


\section{Conclusions.}

Synthesis, characterization, and a priori modelling of mesotetraalkylporphyrin SAMs on HOPG as a function of alkyl chain length has revealed basic understanding of the factors controlling polymorphism, challenges for the experimental characterization of SAMs, and provided insight into computational models and their accuracy. L-type polymorphs are found to dominate SAMs of longer chain-length molecules, with calculations predicting that these become progressively more stable as the chain length increases. For chain lengths $m>15$, a "crystallization" of the alkyl chains occurs, allowing this feature to determine SAM structure in an ordered and predictable way. For shorter chains, the structure can rearrange to accommodate specific chain-length and chain-orientation effects, maintaining unexpected stability for the $\mathrm{L}$ polymorph whilst also facilitating production of $\mathrm{M}$ polymorphs of many forms. An odd/even effect destabilizes the $\mathrm{L}$ polymorph of $\mathrm{C}_{12} \mathrm{P}$, making its $\mathrm{M}$ variant more stable. Difficulty in imaging regular SAMs by STM for $m<11$ is interpreted as arising through chaotic competition between many geometrically dissimilar structures preventing ordering rather than to intrinsically weak binding.

While the calculated free energies of formation are similar to observed ones and the likely errors in the calculations are expected to exceed these differences, predictions of critical SAM properties can now be made that rival the quality of experimentally determined properties. As these properties control SAM formation and polymorphism, better experimental methods are required for measuring free energies, and free-energy components such as enthalpies and entropies, for SAM formation. This presents a significant challenge as fully formed SAMs of these porphyrins are under kinetic rather than thermodynamic control. ${ }^{5-7,9-19}$ Previously we have hypothesised that thermodynamic control dominates the initial few seconds of SAM self assembly. ${ }^{1}$ Using this assumption, herein we are able to explain all the known qualitative properties of SAM formation. However, the calculations also provide quantitative predictions of the effects of thermodynamic control that could be tested when advances in experimental techniques make this feasible. Exploitation of the recently discovered ${ }^{22}$ ability of $\mathrm{Co}$ (II) porphyrins on HOPG to complex $\mathrm{O}_{2}$, based on our predicted SAM structures may present such an opportunity.

It is striking that two very different computational methods, a $\mathrm{QM} / \mathrm{MM}$ one including empirical force fields and PBE-D3, predict very similar properties for the chain-length dependence of SAM formation and polymorphism. Yet in many ways these methods can be improved. Critical to both is the use of the very simple surface-area and solvent-density based solvent dispersion formula of Floris et al., ${ }^{44}$ which from the presented results appears to be accurate to at least 15\%. The QM/MM method has the advantage of computational efficiency and the ability to treat incommensurate SAMs. While in principle PBED3 can be applied directly to evaluate thermodynamic corrections to the free energy ${ }^{56}$ even in solution ${ }^{53}$ application to tetraalkylporphyrin and similarly sized SAMs remains impractical. Nevertheless, PBE-D3 is generally applicable and connects with state of the art methods used across chemical research, suggesting that one day it may become also a standard standalone tool for investigating hydrophobic SAMs and other forms of large-scale self assembly such as polymer and protein folding.
A general problem with calculations, however, is the generation of initial structures for consideration. Here 40 possibilities for the $\mathrm{M}$ polymorphs were generated by systematically sampling the major torsional variables that had been manually identified as controlling the overall SAM structure. Fully automated methods are needed, however, either by full space sampling ${ }^{57,58}$ or else perhaps like those used in protein-structure conformational searching. ${ }^{59-61}$ The large number of possible conformational variants is a feature common to SAMS of large molecules and to proteins, with automated approaches such as molecular dynamics simulations not guaranteed to provide escape from deep local minima. In particular, the Mc structure for $\mathrm{C}_{13} \mathrm{P}$ has unique orientational properties not shared by any other optimized structures (see Fig. 5 and SI Sect. S4) and yet provides a sharp but very deep local minimum structure that could only be found by some robust conformational search algorithm.

\section{ASSOCIATED CONTENT}

\section{Supporting Information}

Provided are full details of the synthesis, characterization, and STM imaging, as well as full details of the computational methods, energetics, and optimized structures. This material is available free of charge via the Internet at http://pubs.acs.org.

\section{AUTHOR INFORMATION}

\section{Corresponding Author}

Email reimers@shu.edu.cn, Jeffrey.Reimers@uts.edu.au

\section{ACKNOWLEDGMENT}

We thank the Australian Research Council for funding this research (grants LP0455238, DP12010259 and DE140100550) and National Computational Infrastructure (NCI) and INTERSECT for provision of computing resources. J.A.A.W.E. thanks the Council for the Chemical Sciences of the Netherlands Organization for Scientific Research (CW-NWO) for a Vidi grant (700.58.423), and the European Research Council for an ERC Starting Grant (NANOCAT-259064), and the Ministry of Education, Culture and Science (Gravity program 024.001.035).

\section{References}

(1) Reimers, J. R.; Panduwinata, D.; Visser, J.; Chin, Y.; Tang, C.; Goerigk, L.; Ford, M. J.; Sintic, M.; Sum, T.-J.; Coenen, M. J. J.; et al. A Priori Calculations of the Free Energy of Formation from Solution of Polymorphic Self-Assembled Monolayers. Proc. Nat. Acad. Sci. 2015, 112, E6101-E6110.

(2) Katsonis, N.; Vicario, J.; Kudernac, T.; Visser, J.; Pollard, M. M.; Feringa, B. L. Self-Organized Monolayer of MesoTetradodecylporphyrin Coordinated to Au(111). J. Am. Chem. Soc. 2006, 128, 15537-15541

(3) Visser, J.; Katsonis, N.; Vicario, J.; Feringa, B. L. TwoDimensional Molecular Patterning by Surface-Enhanced Zn-Porphyrin Coordination. Langmuir 2009, 25, 5980-5985.

(4) Chin, Y.; Panduwinata, D.; Sintic, M.; Sum, T. J.; Hush, N. S.; Crossley, M. J.; Reimers, J. R. Atomic-Resolution Kinked Structure of an Alkylporphyrin on Highly Ordered Pyrolytic Graphite. J. Phys. Chem. Lett. 2011, 2, 62-66.

(5) Coenen, M. J. J.; Cremers, M.; Boer, D. d.; Bruele, F. J. v. d.; Khoury, T.; Sintic, M.; Crossley, M. J.; Enckevort, W. J. P. v.; Hendriksen, B. L. M.; Elemans, J. A. A. W.; et al. Little Exchange at the Liquid/Solid Interface: Defect-Mediated Equilibration of 
Physisorbed Porphyrin Monolayers. Chem. Commun. 2011, 47, 96669668.

(6) Coenen, M. J. J.; den Boer, D.; van den Bruele, F. J.; Habets, T.; Timmers, K. A. A. M.; van der Maas, M.; Khoury, T.; Panduwinata, D.; Crossley, M. J.; Reimers, J. R.; et al. Polymorphism in Porphyrin Monolayers: The Relation between Adsorption Configuration and Molecular Conformation. Phys. Chem. Chem. Phys. 2013, 15, 12451. 12458.

(7) Bhattarai, A.; Mazur, U.; Hipps, K. W. A Single Molecule Level Study of the Temperature-Dependent Kinetics for the Formation of Metal Porphyrin Monolayers on Au(111) from Solution. J. Am. Chem. Soc. 2014, 136, 2142-2148.

(8) Mazur, U.; Hipps, K. W. Kinetic and Thermodynamic Processes of Organic Species at the Solution-Solid Interface: The View through an Stm. Chemical Communications 2015, 51, 4737-4749.

(9) Hu, F.; Gong, Y.; Zhang, X.; Xue, J.; Liu, B.; Lu, T.; Deng, K.; Duan, W.; Zeng, Q.; Wang, C. Temperature-Induced Transitions of Self-Assembled Phthalocyanine Molecular Nanoarrays at the SolidLiquid Interface: From Randomness to Order. Nanoscale 2014, 6, 4243 4249 .

(10) Blunt, M. O.; Adisoejoso, J.; Tahara, K.; Katayama, K.; Van der Auweraer, M.; Tobe, Y.; De Feyter, S. Temperature-Induced Structural Phase Transitions in a Two-Dimensional Self-Assembled Network. J. Am. Chem. Soc. 2013, 135, 12068-12075.

(11) Jahanbekam, A.; Vorpahl, S.; Mazur, U.; Hipps, K. W. Temperature Stability of Three Commensurate Surface Structures of Coronene Adsorbed on $\mathrm{Au}(111)$ from Heptanoic Acid in the 0 to $60^{\circ} \mathrm{C}$ Range. J. Phys. Chem. C 2013, 117, 2914-2919.

(12) Friesen, B. A.; Bhattarai, A.; Mazur, U.; Hipps, K. W. Single Molecule Imaging of Oxygenation of Cobalt Octaethylporphyrin at the Solution/Solid Interface: Thermodynamics from Microscopy. J. Am. Chem. Soc. 2012, 134, 14897-14904.

(13) English, W. A.; Hipps, K. W. Stability of a Surface Adlayer at Elevated Temperature: Coronene and Heptanoic Acid on $\mathrm{Au}(111)$. J. Phys. Chem. C 2008, 112, 2026-2031.

(14) Miyake, Y.; Nagata, T.; Tanaka, H.; Yamazaki, M.; Ohta, M.; Kokawa, R.; Ogawa, T. Entropy-Controlled 2d Supramolecular Structures of N,N '-Bis(N-Alkyl)-Naphthalenediimides on a Hopg Surface. Acs Nano 2012, 6, 3876-3887.

(15) Ikeda, T.; Asakawa, M.; Miyake, K.; Goto, M.; Shimizu, T. Scanning Tunneling Microscopy Observation of Self-Assembled Monolayers of Strapped Porphyrins. Langmuir 2008, 24, 12877-12882.

(16) Otsuki, J.; Kawaguchi, S.; Yamakawa, T.; Asakawa, M.; Miyake, K. Arrays of Double-Decker Porphyrins on Highly Oriented Pyrolytic Graphite. Langmuir 2006, 22, 5708-5715.

(17) Ikeda, T.; Asakawa, M.; Goto, M.; Miyake, K.; Ishida, T.; Shimizu, T. Stm Observation of Alkyl-Chain-Assisted Self-Assembled Monolayers of Pyridine-Coordinated Porphyrin Rhodium Chlorides. Langmuir 2004, 20, 5454-5459.

(18) Gutzler, R.; Sirtl, T.; Dienstmaier, J. F.; Mahata, K.; Heckl, W. M.; Schmittel, M.; Lackinger, M. Reversible Phase Transitions in Self-Assembled Monolayers at the Liquid-Solid Interface: TemperatureControlled Opening and Closing of Nanopores. J. Am. Chem. Soc. 2010, 132, 5084-5090.

(19) Sirtl, T.; Song, W.; Eder, G.; Neogi, S.; Schmittel, M.; Heckl, W. M.; Lackinger, M. Solvent-Dependent Stabilization of Metastable Monolayer Polymorphs at the Liquid-Solid Interface. ACS Nano 2013, 7, 6711-6718.

(20) Song, W.; Martsinovich, N.; Heckl, W. M.; Lackinger, M. Thermodynamics of 4,4[Prime or Minute]-Stilbenedicarboxylic Acid Monolayer Self-Assembly at the Nonanoic Acid-Graphite Interface. Phys. Chem. Chem. Phys. 2014, 16, 13239-13247.

(21) Hulsken, B.; Van Hameren, R.; Thordarson, P.; Gerritsen, J. W.; Nolte, R. J. M.; Rowan, A. E.; Crossley, M. J.; Elemans, J. A. A. W.; Speller, S. Scanning Tunneling Microscopy and Spectroscopy Studies of Porphyrins at Solid-Liquid Interfaces. Japanese Journal of Applied Physics, Part 1: Regular Papers and Short Notes and Review Papers 2006, 45, 1953-1955.
(22) Friesen, B. A.; Bhattarai, A.; Mazur, U.; Hipps, K. W. Single Molecule Imaging of Oxygenation of Cobalt Octaethylporphyrin at the Solution/Solid Interface: Thermodynamics from Microscopy. J. Am. Chem. Soc. 2012, 134, 14897-14904.

(23) Lei, S.; Tahara, K.; De Schryver, F. C.; Van der Auweraer, M.; Tobe, Y.; De Feyter, S. One Building Block, Two Different Supramolecular Surface-Confined Patterns: Concentration in Control at the Solid-Liquid Interface. Angew. Chem., Int. Ed. 2008, 47, $2964-$ 2968.

(24) Bellec, A.; Arrigoni, C.; Schull, G.; Douillard, L.; FioriniDebuisschert, C.; Mathevet, F.; Kreher, D.; Attias, A.-J.; Charra, F. Solution-Growth Kinetics and Thermodynamics of Nanoporous SelfAssembled Molecular Monolayers. J. Chem. Phys. 2011, 134, 124702/124701-124707.

(25) Mammen, M.; Shakhnovich, E. I.; Whitesides, G. M. Using a Convenient, Quantitative Model for Torsional Entropy to Establish Qualitative Trends for Molecular Processes That Restrict Conformational Freedom. J. Org. Chem. 1998, 63, 3168-3175.

(26) Mammen, M.; Shakhnovich, E. I.; Deutch, J. M.; Whitesides, G. M. Estimating the Entropic Cost of Self-Assembly of Multiparticle Hydrogen-Bonded Aggregates Based on the Cyanuric Acid·Melamine Lattice. J. Org. Chem. 1998, 63, 3821-3830.

(27) Rodziewicz, P.; Meyer, B. Interplay between MoleculeMolecule and Molecule-Substrate Interactions: First-Principles Study of Fluoroform Aggregates on a Hexagonal Ice (0001) Surface. Phys. Chem. Chem. Phys. 2014, 16, 940-954.

(28) Killian, B. J.; Kravitz, J. Y.; Gilson, M. K. Extraction of Configurational Entropy from Molecular Simulations Via an Expansion Approximation. J. Chem. Phys. 2007, 127, 024107.

(29) Hensen, U.; Lange, O. F.; Grubmueller, H. Estimating Absolute Configurational Entropies of Macromolecules: The Minimally Coupled Subspace Approach. Plos One 2010, 5, e9179/9171-9178.

(30) Künzel, D.; Groß, A. Influence of the Solvent on the Stability of Bis(Terpyridine) Structures on Graphite. Beilstein Journal of Nanotechnology 2013, 4, 269-277.

(31) Meier, C.; Roos, M.; Künzel, D.; Breitruck, A.; Hoster, H. E.; Landfester, K.; Gross, A.; Behm, R. J.; Ziener, U. Concentration and Coverage Dependent Adlayer Structures: From Two-Dimensional Networks to Rotation in a Bearing. J. Phys. Chem. C 2010, 114, 1268 1277

(32) Becke, A. D. Density-Functional Thermochemistry. Iii. The Role of Exact Exchange. J. Chem. Phys. 1993, 98, 5648-5652.

(33) Hehre, W. J.; Ditchfield, R.; Pople, J. A. Self-Consistent Molecular Orbital Methods. Xii. Further Extensions of Gaussian-Type Basis Sets for Use in Molecular Orbital Studies of Organic Molecules J. Chem. Phys. 1972, 56, 2257-2261.

(34) Weiner, S. J.; Kollman, P. A.; Case, D. A.; Singh, U. C.; Ghio, C.; Alagona, G.; S. Profeta, J.; Weiner, P. A New Force Field for Molecular Mechanical Simulation of Nucleic Acids and Proteins. J. Am. Chem. Soc. 1984, 106, 765-784.

(35) Battezzati, L.; Pisani, C.; Ricca, F. Equilibrium Conformation and Surface Motion of Hydrocarbon Molecules Physisorbed on Graphite. J. Chem. Soc., Faraday Trans. 2 1975, 71, 1629-1639.

(36) Perdew, J. P.; Wang, Y. Accurate and Simple Analytic Representation of the Electron-Gas Correlation Energy. Phys. Rev. B 1992, 45, 13244-13249.

(37) Grimme, S.; Antony, J.; Ehrlich, S.; Krieg, H. A Consistent and Accurate $\mathrm{Ab}$ Initio Parametrization of Density Functional Dispersion Correction (Dft-D) for the 94 Elements H-Pu. J. Chem. Phys. 2010, 132, 154104.

(38) Grimme, S.; Ehrlich, S.; Goerigk, L. Effect of the Damping Function in Dispersion Corrected Density Functional Theory. J. Comput. Chem 2011, 32, 1456-1465.

(39) Risthaus, T.; Grimme, S. Benchmarking of London Dispersion-Accounting Density Functional Theory Methods on Very 
Large Molecular Complexes. J. Chem. Theory Comput. 2013, 9, 15801591.

(40) Moellmann, J.; Grimme, S. Dft-D3 Study of Some Molecular Crystals. J. Phys. Chem. C 2014, 118, 7615-7621.

(41) Goerigk, L. How Do Dft-Dcp, Dft-Nl, and Dft-D3 Compare for the Description of London-Dispersion Effects in Conformers and General Thermochemistry? J. Chem. Theory Comput. 2014, 10, 968-980.

(42) Klimeš, J.; Michaelides, A. Perspective: Advances and Challenges in Treating Van Der Waals Dispersion Forces in Density Functional Theory. J. Chem. Phys. 2012, 137, 120901.

(43) Sure, R.; Antony, J.; Grimme, S. Blind Prediction of Binding Affinities for Charged Supramolecular Host-Guest Systems: Achievements and Shortcomings of Dft-D3. J. Phys. Chem. B 2014, 118, 3431-3440.

(44) Floris, F. M.; Tomasi, J.; Pascual Ahuir, J. L. Dispersion and Repulsion Contributions to the Solvation Energy: Refinements to a Simple Computational Model in the Continuum Approximation. J. Computat. Chem. 1991, 12, 784-791.

(45) Reimers, J. R.; Ford, M. J.; Goerigk, L. Problems, Successes and Challenges for the Application of Dispersion-Corrected DensityFunctional Theory Combined with Dispersion-Based Implicit Solvent Models to Large-Scale Hydrophobic Self-Assembly and Polymorphism. Mol. Simul. 2015, in press DOI 10.1080/08927022.2015.1066504, 1-17.

(46) Crossley, M. J.; Thordarson, P.; Bannerman, J. P.; Maynard, P. J. A Convenient Procedure for Moderate-Scale Rothemund Synthesis of Lipophilic Porphyrins: An Alternative to the Adler-Longo and Lindsey Methodologies. J. Porphyrins Phthalocyanines 1998, 2, 511 516.

(47) Puigmartí-Luis, J.; Minoia, A.; Uji-I, H.; Rovira, C.; Cornil, J.; De Feyter, S.; Lazzaroni, R.; Amabilino, D. B. Noncovalent Control for Bottom-up Assembly of Functional Supramolecular Wires. J. Am. Chem. Soc. 2006, 128, 12602-12603.

(48) Frisch, M. J.; Trucks, G. W.; Schlegel, H. B.; Scuseria, G. E.; Robb, M. A.; Cheeseman, J. R.; Montgomery, J. A.; Vreven, T.; Kudin, K. N.; Burant, J. C.; et al. Gaussian 09, Revision C.09; Gaussian, Inc., Pittsburgh PA, 2009.

(49) Dapprich, S.; Komaromi, I.; S., B. K.; Morokuma, K.; Frisch, M. J. A New Oniom Implementation in Gaussian98. Part I. The Calculation of Energies, Gradients, Vibrational Frequencies and Electric Field Derivatives. J. Mol. Struct. (THEOCHEM) 1999, 461-462, $1-21$.

(50) Ochterski, J. W.; GAUSSIAN Inc.

(51) Kresse, G.; Hafner, J. Ab Initio Molecular Dynamics for Liquid Metals. Phys. Rev. B 1993, 47, 558-561.

(52) Kresse, G.; Furthmüller, J. Efficiency of Ab-Initio Total Energy Calculations for Metals and Semiconductors Using a PlaneWave Basis Set. Comput. Mat. Sci. 1996, 6, 15-50.

(53) Mathew, K.; Sundararaman, R.; Letchworth-Weaver, K.; Arias, T. A.; Hennig, R. G. Implicit Solvation Model for DensityFunctional Study of Nanocrystal Surfaces and Reaction Pathways. J. Chem. Phys. 2014, 140, 084106.

(54) Tersoff, J.; Hamann, D. R. Theory and Application for the Scanning Tunneling Microscope Phys. Rev. Lett. 1983, 50, 1998-2001.

(55) Ilan, B.; Florio, G. M.; Hybertsen, M. S.; Berne, B. J.; Flynn, G. W. Scanning Tunneling Microscopy Images of Alkane Derivatives on Graphite: Role of Electronic Effects. Nano Lett. 2008, 8, 3160-3165.

(56) Reuter, K.; Scheffler, M. Composition, Structure, and Stability of Ruo2 (110) as a Function of Oxygen Pressure. Physical Review B 2001, 65, 035406.

(57) Ouyang, R.; Yan, J.; Jensen, P. S.; Ascic, E.; Gan, S.; Tanner, D. A.; Mao, B.; Ni, L.; Zhang, J.; Tang, C.; et al. Intermixed Adatom and Surface Bound Adsorbates in Regular Self-Assembled Monolayers of Racemic 2-Butanethiol on Au(111) ChemPhysChem 2015, 16, 928 932.

(58) Yan, J.; Ouyang, R.; Jensen, P. S.; Ascic, E.; Tanner, D. A.; Mao, B.; Zhang, J.; Tang, C.; Hush, N. S.; Ulstrup, J.; et al. Controlling the Stereochemistry and Regularity of Butanethiol Self-Assembled Monolayers on Au(111) J. Amer. Chem. Soc. 2014, 136, 17087-17094.
(59) Ando, M.; Akiyama, Y.; Matsuda, H. Conformational Search and Potential Energy Analysis of Protein B-Hairpin Formations by Parallel Exhaustive Tree Search. Genome Inf. Ser. 2001, 12, 362-363.

(60) Blum, B.; Jordan, M. I.; Baker, D. Feature Space Resampling for Protein Conformational Search. Proteins: Struct., Funct., Bioinf. 2010, 78, 1583-1593.

(61) Olson, B.; Molloy, K.; Shehu, A. In Search of the Protein Native State with a Probabilistic Sampling Approach. J. Bioinf. Comput. Biol. 2011, 9, 383-398. 
SYNOPSIS TOC

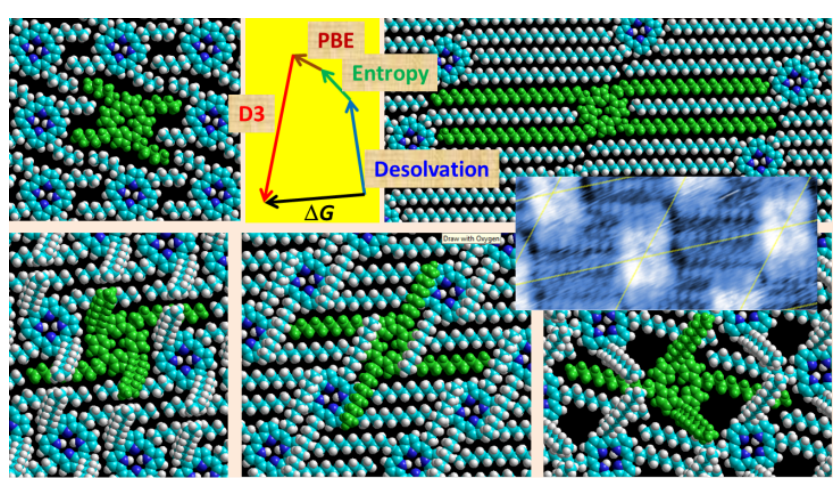

